\title{
SOME PROBLEMS OF THE DEVELOPMENT OF DAIRY INDUSTRY IN RUSSIAN FEDERATION
}

\author{
Ekaterina G. Bodrova \\ International Institute of Design and Service, Chelyabinsk, Russian Federation
}

\begin{abstract}
The research aim is to highlight some of the problems of the development of dairy industry in Russian Federation. The paper highlights the main of the state target subprogram "Development of milk production and dairy products for 2015-2020", according to which the necessary is more dynamic development of dairy products that meets the population's needs. The research is focused in the characteristic of distribution of milk consumption in Russian Federation by regions. So it is established that only 6 regions of the country had the level of actual consumption of milk and dairy products as close as possible to the recommendations on rational norms of consumption of food products. The paper highlights the main points that led to the fact that the dairy industry of the Russian Federation is in a difficult situation. The scheme of distribution of the main problems of dairy industry on levels is made: level of the state, level of the enterprise and level of the consumer; also some problems of milk production are given. During the scheme, one of the main and important points is formulated: low investment attractiveness of dairy production. The situation that the structure of milk production by categories of farms has considerably changed. In conclusion, the article presents the main state support, as a result it will be possible to increase production in the dairy segment in order to meet the population's needs with domestic food products, and industry - raw materials. Results: the allocation of subsidies; reduction of administrative burden; dissemination of opinions about the usefulness and necessity of milk.

Key words: milk, dairy industry, milk production, dairy milk processing plant, problems, state support.

Citation. Bodrova E.G. Some Problems of the Development of Dairy Industry in Russian Federation. Vestnik Volgogradskogo gosudarstvennogo universiteta. Seriya 3, Ekonomika. Ekologiya [Science Journal of Volgograd State University. Global Economic System], 2018, vol. 20, no. 4, pp. 118-125. (in Russian). DOI: https://doi.org/ 10.15688/jvolsu3.2018.4.11
\end{abstract}

УДК 338.439 .4

Дата поступления статьи: 17.10.2018

ББК $65.30 ; 65.32$ Дата принятия статьи: 28.11.2018

\section{НЕКОТОРЫЕ ПРОБЛЕМЫ РАЗВИТИЯ МОЛОЧНОГО ПРОИЗВОДСТВА В РОССИИ}

\author{
Екатерина Григорьевна Бодрова \\ Международный институт дизайна и сервиса, г. Челябинск, Российская Федерация
}

\begin{abstract}
Аннотация. Основной задачей исследования является освещение некоторых из проблем, которые сопровождают развитие молочного производства в России. В статье приведены основные положения Государственной целевой подпрограммы «Развитие производства молока и молочной продукции на 2015-2020 годы», согласно которой требуется более динамичное развитие производства молочных продуктов, необходимых дудвлетворения потребностей населения. Дана характеристика распределения потребления молока в Российской Федерации по регионам. Так, установлено, что только в 6 регионах страны уровень фактического потребления молока и молочных продуктов максимально приближен к рекомендациям по рациональным нормам потребления пищевых продуктов. В работе выделены основные моменты, которые привели к тому, что молочная отрасль РФ находится в непростом положении. Составлена схема распределения основных проблем молочной отрасли по уровням: уровень государства, уровень предприятия и уровень потребителя; также сформулированы некоторые проблемы молочной отрасли. В схеме выражен один из основных и
\end{abstract}


важных моментов - невысокая инвестиционная привлекательность молочного производства. В публикации раскрыто положение о том, что в значительной степени изменилась структура производства молока и молочной продукции по категориям хозяйств. В заключении статьи определены основные шаги государства, в результате которых будет возможным наращение производства в молочном сегменте с целью удовлетворения потребностей населения отечественными продуктами питания, а промышленность - сырьевыми ресурсами. К таким действиям относятся: выделение субсидий; снижение административной нагрузки; распространение мнения о полезности и нужности молока.

Ключевые слова: молоко, молочная промышленность, молокоперерабатывающие предприятия, проблемы, государственная поддержка.

Цитирование. Бодрова Е. Г. Некоторые проблемы развития молочного производства в России // Вестник Волгоградского государственного университета. Серия 3, Экономика. Экология. - 2018. - Т. 20, № 4. C. 118-125.-DOI: https://doi.org/10.15688/jvolsu3.2018.4.11

\section{Цель и методика исследования}

Цель исследования заключается в рассмотрении и анализе проблем развития молочного производства в России. Методы исследования: экономико-правового анализа, статистический. Многие российские ученые ( С.А. Иванов [2; 8], О.А. Давыдова [7], Д.Ю. Панкратова [3; 11], А.В. Видякин [5]) рассматривают в своих публикациях основные проблемы функционирования рынка молока, специфику развития молочного производства, а также функции государственного регулирования молокоперерабатывающей промышленности.

\section{Результаты исследования}

В 2015 г. была разработана Государственная целевая подпрограмма «Развитие производства молока и молочной продукции на 2015-2020 годы», цель которой сформулирована следующим образом: «максимально возможное приближение к значениям целевых показателей Доктрины продовольственной безопасности Российской Федерации в сфере производства продукции молочного животноводства; повышение инвестиционной привлекательности молочного скотоводства и молокоперерабатывающей промышленности; обеспечение комплексного и сбалансированного развития молочной отрасли и повышение эффективности производства и переработки молока» [12].

Если говорить о числовом выражении, ожидаемые результаты реализации подпрограммы представлены на рисунке 1 .

Надо отметить, что потребление молочных продуктов в Российской Федерации различается от региона к региону. Данное поло- жение есть результат дифференциации сельского хозяйства по территории сначала Советского союза, а сейчас уже и Российской Федерации. Так, еще в СССР сложилось распределение молочной промышленности по регионам страны [9; 10]. Рекомендации по рациональным нормам потребления пищевых продуктов, отвечающих современным требованиям здорового питания от 19 августа 2016 г. представлены на рисунке 2 [13].

Самый высокий уровень потребления молока и молочных продуктов на одного человека в России зафиксирован в Республике Татарстан (362 кг/год) и Алтайском крае (326 кг/год). Еще в 4 регионах уровень потребления молочных продуктов наиболее приближен к норме [14] (см. табл. 1).

Вызывает опасение, что в 75 областях России (почти во всех) уровень потребления ниже нормы, то есть население этих регионов потребляет молоко и молочную продукцию в ниже рационально необходимом количестве (см. табл. 2).

Молочная отрасль в РФ в данный момент находится в непростом положении. Выделим основные моменты, которые привели к этой ситуации. Представим их схематично на рисунке 3 .

Молочное производство Российской Федерации пребывает в сложном состоянии нестабильности. Как обозначено на рисунке 3, к этому привело несколько причин. Одна из ключевых - невысокая инвестиционная привлекательность молочного производства даже по сравнению с производством птицы и свиней. На фоне обесценивания национальной валюты в конце 2014 г. это привело к снижению объемов инвестирования в обновление молочной отрасли [15]. Впоследствии в 2015 г. уве- 


\section{УПРАВЛЕНИЕ ЭКОНОМИЧЕСКИМ РАЗВИТИЕМ}

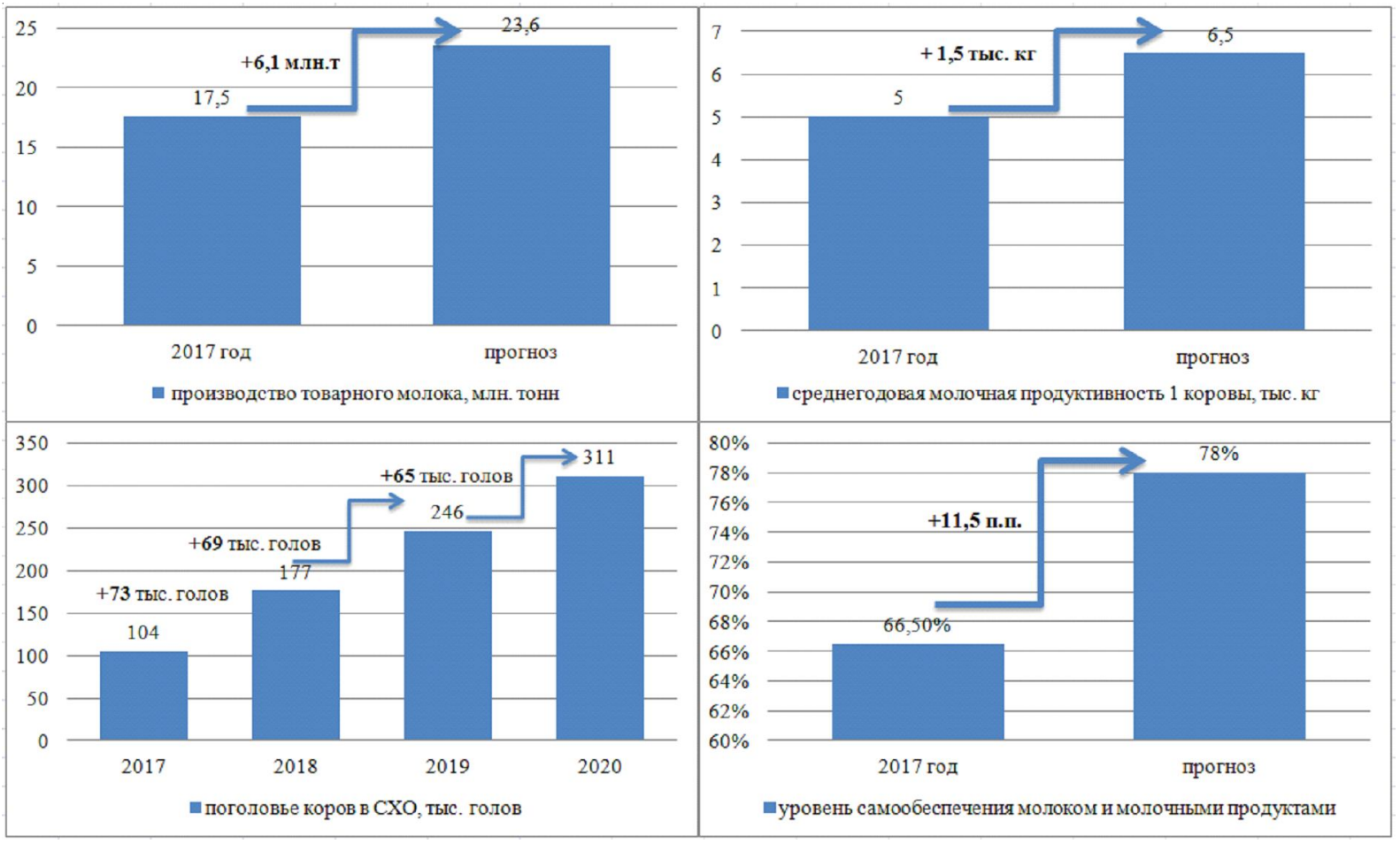

Рис. 1. Целевые показатели программы «Развитие производства молока и молочной продукции на 2015-2020 годы»

Примечание. Составлено автором по: [12].

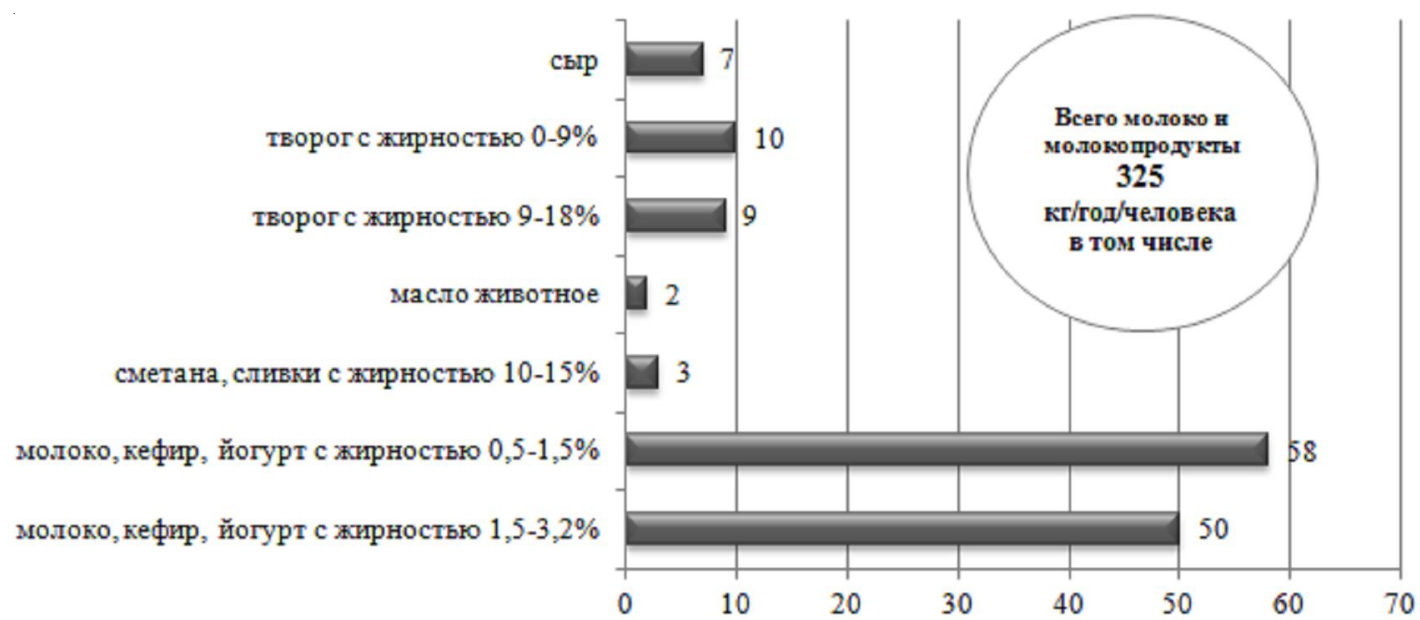

Рис. 2. Рекомендации по рациональным нормам потребления пищевых продуктов Примечание. Составлено по: [13].

Таблица 1

Потребление основных продуктов питания (в расчете на 1 человека)

\begin{tabular}{|l|c|c|}
\hline \multicolumn{1}{|c|}{ Регион } & $\begin{array}{c}\text { Потребление молока } \\
\text { и молочных продуктов } \\
\text { (кг/год/человек) }\end{array}$ & $\begin{array}{c}\text { Место, занимаемое } \\
\text { в Российской Феде- } \\
\text { рации (2016 год) }\end{array}$ \\
\hline Оренбургская область & 304 & 4 \\
\hline Карачаево-Черкесская Республика & 310 & 3 \\
\hline Город Санкт-Петербург & 312 & 2 \\
\hline Республика Башкортостан & 313 & 1 \\
\hline
\end{tabular}

Примечание. Составлено автором по [14]. 
Е.Г. Бодрова. Некоторые проблемы развития молочного производства в России

Таблиияа 2

\section{Группировка регионов РФ по потреблению молока и молочных продуктов}

в 2016 году

\begin{tabular}{|c|c|c|c|}
\hline $\begin{array}{c}\text { № } \\
\text { группы }\end{array}$ & $\begin{array}{c}\text { Потребление молока } \\
\text { и молочных продуктов, кг/год }\end{array}$ & $\begin{array}{c}\text { Количество } \\
\text { Регионов РФ }\end{array}$ & $\begin{array}{c}\text { Уровень потребления молока } \\
\text { и молочных продуктов, \% }\end{array}$ \\
\hline 1 & $106-143$ & 4 & $33-42$ \\
\hline 2 & $143-179$ & 9 & $47-55$ \\
\hline 3 & $179-216$ & 20 & $56-66$ \\
\hline 4 & $216-252$ & 23 & $68-77$ \\
\hline 5 & $252-289$ & 19 & $78-88$ \\
\hline 6 & $289-325$ & 5 & $90-96$ \\
\hline 7 & $325-362$ & 2 & $96-111$ \\
\hline
\end{tabular}

Примечание. Рассчитано автором по [14].

\begin{tabular}{c} 
понке \\
ПотребиТеЛЯ \\
Увеличение доли \\
Фальсификата на молочном \\
поние \\
потребительского спроса на \\
молоко и молочную \\
продукцию на фоне \\
снижения покупательной \\
способности денежных \\
доходов населения \\
\hline Население обеспечено \\
молоком отечестенного \\
производства на 83\% при \\
пороговом значении, \\
предусмотренном Доктриной \\
продовольственной \\
безопасности, - 90\% \\
\hline
\end{tabular}

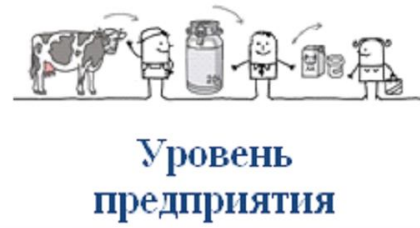

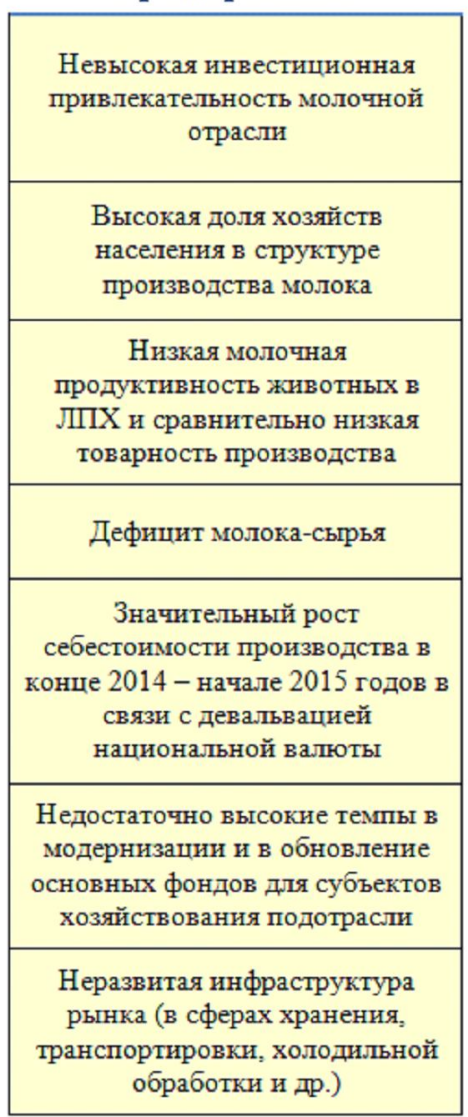

Уровень государства

Снижение объемов инвестиций в модернизацию и развитие производства и переработки молока

Зависимость отечественной молочной отрасли от импорта молока и молочных продуктов

Высокая конкурентоспособность белорусской продукции

Рис. 3. Некоторые проблемы развития молочного производства в России

Примечание. Составлено автором.

личилась стоимость кредитных ресурсов, возросла себестоимость производства молока как результат совокупности следующих факторов: сокращение поголовья КРС и увеличения доли хозяйств населения при низкой мо- лочной продуктивности животных в ЛПХ и снижении товарности производства молока. Как результат, мы наблюдаем дефицит молока-сырья, высокую долю импортной продукции (см. рис. 4). 


\section{УПРАВЛЕНИЕ ЭКОНОМИЧЕСКИМ РАЗВИТИЕМ}

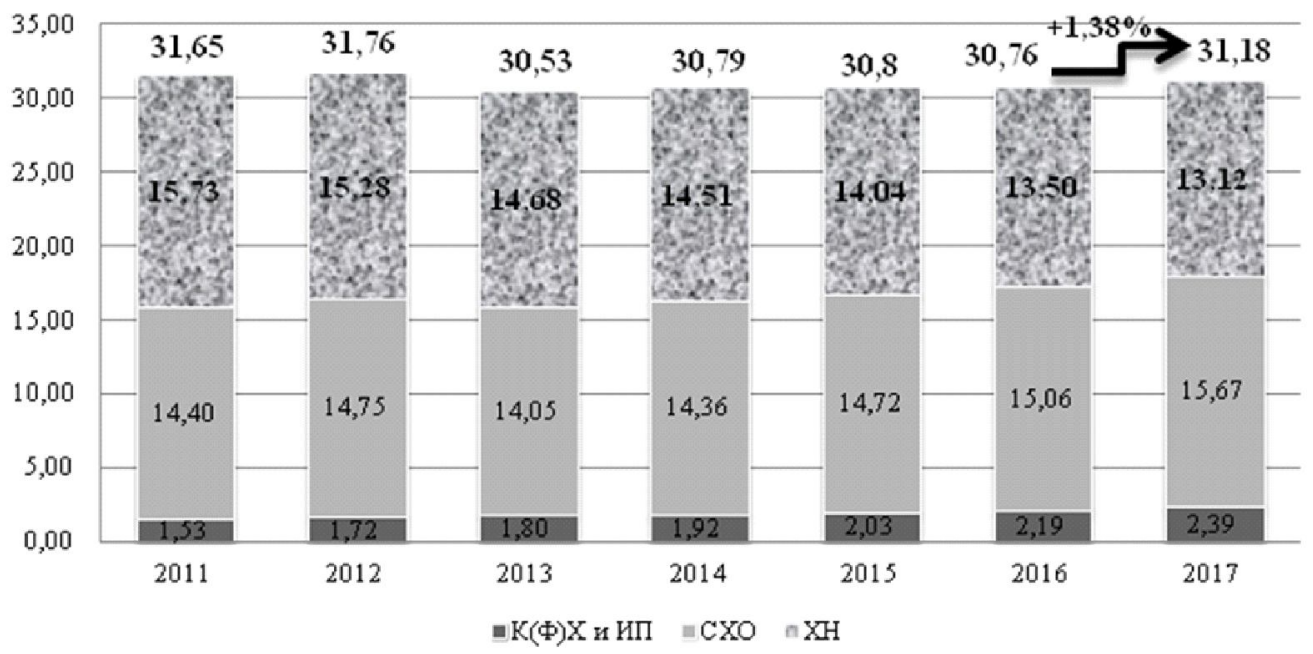

Рис. 4. Динамика производства молока

Примечание. Составлено автором по [14].

Также важный момент, который характеризует специфику молочного производства, заключается в том, что в значительной степени изменилась структура производства молока и молочной продукции по категориям хозяйств. С 1990 г. наблюдается усиление снижения концентрации и натурализации [12]. Снижение доли сельскохозяйственных организаций в общем объеме производства молока составило 26 процентных пунктов по сравнению с 1990 годом (см. рис. 5). Начиная с 2000-х гг., в Российской Федерации, половина молока производится в крестьянских (фермерских) хозяйствах и у индивидуальных предпринимателей, а также в хозяй- ствах населения. Надо отметить, что эти категории хозяйств не могут признаваться значимыми субъектами для общего рынка молока, потому что их деятельность нацелена на обеспечение молочными продуктами самих себя.

К главным проблемам развития предприятий молочной промышленности в России можно отнести:

- устаревание материально-технической базы (большинство основных производственных фондов на молокоперерабатывающих предприятиях были построены во второй половине прошлого века) и наряду с этим низкая модернизация основных средств [1; 6];
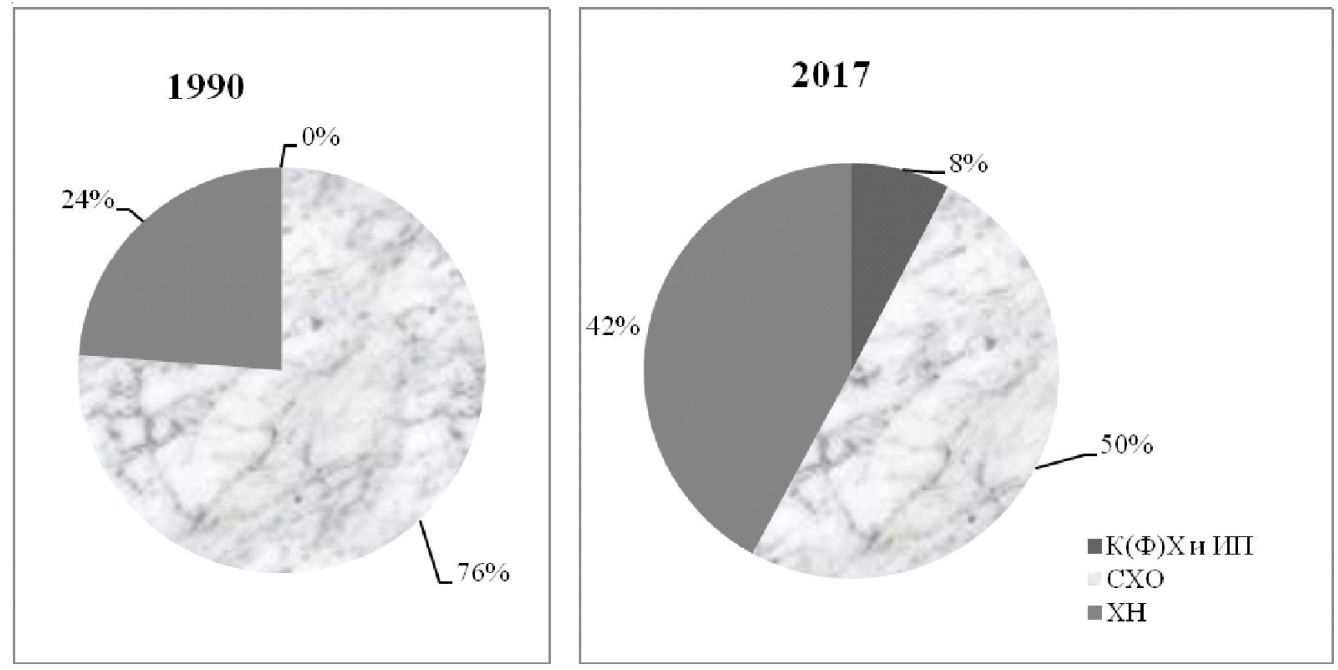

Рис. 5. Структура производства молока и молочной продукции по категориям хозяйств Примечание. Составлено автором по [14]. 
- низкий удельный вес молока-сырья высшего сорта, при этом в данный момент нет адекватного контроля качества сырого молока, в состав которого зачастую включаются жиры растительного происхождения.

- увеличение доли фальсификата на молочном рынке.

- слабая обеспечивающая структура рынка в области транспортировки, современной упаковки, хранения, а также обработки молочных продуктов.

\section{Выводы и рекомендации}

Тем не менее производители молочной продукции в России имеют потенциал увеличения объемов производства. При норме потребления молочных продуктов 300-330 кг, фактическое потребление составляет от 190 до 250 кг. Однако любое развитие (обновление производственного потенциала, наращивание эффективности молочной отрасли, повышение объемов производства молочных продуктов, увеличение качества молока и, как следствие, снижение существующей зависимости от импорта) невозможно без активного участия государства в этих процессах. Ocновные шаги государства:

1. Выделение субсидий в виде краткосрочных и долгосрочных кредитов, возмещение затрат на обновление основных производственных фондов молокоперерабатывающих предприятий и предприятий молочного скотоводства.

2. Оказание поддержки при выплате процентов по инвестиционным кредитам.

3. Разработка мероприятий по снижению административной нагрузки.

4. Доработка существующей долгосрочной стратегии развития молочной отрасли России с набором инструментов регулирования и выработкой последующих мер поддержки отрасли.

5. Введение мер по наказанию за нарушение технического регламента производства молочной продукции.

6. Разработка социальной программы по распространению мнения о полезности и нужности молока.

Внимательный подход, а также выработка комплексных и консолидированных реше- ний приведет к обеспечению развития молочной отрасли, а также позволит создать условия для увеличения объемов производства молока и молочных продуктов, повысить качество выпускаемой продукции.

\section{СПИСОК ЛИТЕРАТУРЫ}

1. Артемова, Е. И. Детерминанты развития отечественного рынка молока в условиях импортозамещения / Е. И. Артемова, Е. В. Кремянская // Научный журнал КубГАУ - Scientific Journal of KubSAU. - 2016. - № 116. - C. 882-896.

2. Балабайкин, В. Ф. Разработка стратегий устойчивого развития предприятий АПК Челябинской области / В. Ф. Балабайкин, С. А. Иванов // Известия Международной академии аграрного образования. 2015. - № 23. - С. 40-43.

3. Бодрова, Е. Г. Особенности определения эффективности работы молокоперерабатывающего предприятия / Е. Г. Бодрова, Д. Ю. Панкратова // АПК России. - 2016. - № 2 (т. 23). - С. 497-502.

4. Буянова, М. Э. Опыт реализации проектов государственно-частного партнерства регионов РФ в экологической сфере / М. Э. Буянова, И. С. Аверина, Ю. Г. Копылова // Региональная экономика. Юг России. - 2017. - № 3. - С. 140-150.

5. Видякин, А. В. Развитие производства молока и молочной продукции на основе агропромышленной интеграции в Кемеровской области / А. В. Видякин, Н. Ю. Латков // Экономика и предпринимательство. - 2016. - № 10 (ч. 1). - С. 663-667.

6. Груздев, Г. В. Предпосылки импортозамещения молочной продукции. Оценка факторов, оказывающих влияние на эффективность производства молока / Г. В. Груздев, Т. Е. Кирилова // Вестник НГИЭИ. - 2017. - № 9 (76). - С. 125-134.

7. Давыдова, О. А. Модель оценки конкурентоспособности предприятия, производящего молочную продукцию / О. А. Давыдова, С. Л. Сафронов // АПК: проблемы, состояние, развитие : сб. материалов I Всеросс. науч.-практ. конф. - СПб. : Изд-во СПбГАУ, 2011. - С. 95-98.

8. Иванов, С. А. Условия функционирования малых предприятий АПК в свете последних изменений законодательства / С. А. Иванов // Сб. материалов междунар. науч.-практ. конф. ФГБОУ ВО «Южно-Уральский государственный аграрный университет»: Гуманитарные и экономические науки - агропромышленному комплексу России. Троицк, 2017.- С. 43-47.

9. Никонорова, О. С. Специфика функционирования и проблемы развития российского рынка молока и молочной продукции / О. С. Никонорова // Экономические исследования. -2013. -№ 2. -С. 2-22. 
10. Оборин, М. С. Особенности развития инфраструктуры агропромышленного комплекса сельских территорий / М. С. Оборин // Вестник Волгоградского государственного университета. Серия 3, Экономика. Экология. - 2018. - Т. 20, № 2. - С. 5564. - DOI: https://doi.org/10.15688/jvolsu3.2018.2.6.

11. Панкратова, Д. Ю. Развитие сельскохозяйственных кредитных потребительских кооперативов на основе применения комплексного подхода / Д. Ю. Панкратова // В мире научных открытий. 2015. - № 11.5. - С. 1837-1846.

12. Постановление Правительства РФ от 19 декабря 2014 г. № 1421 «О внесении изменений в Государственную программу развития сельского хозяйства и регулирования рынков сельскохозяйственной продукции, сырья и продовольствия на 2013-2020 годы». - Электрон. текстовые дан. - Режим доступа: http:/www.garant.ru/products/ipo/prime/doc/70727272/ (дата обращения: 17.09.2018). - Загл. с экрана.

13. Приказ Министерства здравоохранения РФ от 19 августа 2016 г. № 614 «Об утверждении Рекомендаций по рациональным нормам потребления пищевых продуктов, отвечающих современным требованиям здорового питания». - Электрон. текстовые дан. - Режим доступа: http://www.garant.ru/ products/ipo/prime/doc/71385784/ (дата обращения: 17.09.2018). - Загл. с экрана.

14. Федеральная служба государственной статистики. - Электрон. текстовые дан. - Режим доступа: http://www.gks.ru (дата обращения: 10.09.2018).Загл. с экрана.

15. Шагеев, Д. А. Повышение эффективности инвестиционного проекта промышленного предприятия при помощи управления денежными потоками / Д. А. Шагеев // Вестник Московского университета. Серия 6, Экономика. - 2017. - № 2. - С. 90-106.

16. Schwarzweller, H. K. Dairy Industry Restructuring / H. K. Schwarzweller \& A. P. Davidson // Research in Rural Sociology and Development. N. Y., 2000.-Vol. 8.

\section{REFERENCES}

1. Artemova E.I., Kremyanskaya E.V. Determinanty razvitiya otechestvennogo rynka moloka v usloviyakh importozameshcheniya [Determinants of development of the domestic milk market in terms of import]. Nauchnyy zhurnal KubGAU [Scientific Journal of KubSAU], 2016, no. 116, pp. 882-896.

2. Balabaykin V.F., Ivanov S.A. Razrabotka strategiy ustoychivogo razvitiya predpriyatiy APK Chelyabinskoy oblasti [Development of strategies for sustainable development of agricultural enterprises of the Chelyabinsk region]. Izvestiya Mezhdunarodnoy akademii agrarnogo obrazovaniya [Bulletin of
International Academy of Agrarian Education], 2015, no. 23 , pp. $40-43$.

3. Bodrova E.G., Pankratova D.Yu. Osobennosti opredeleniya effektivnosti raboty molokopererabatyvayushchego predpriyatiya [Determining the efficiency of milk production]. APK Rossii, 2016, no. 2, vol. 23, pp. 497-502.

4. Buyanova M.E., Averina I.S., Kopylova Yu.G. Opyt realizatsii proektov gosudarstvenno-chastnogo partnerstva regionov RF v ehkologicheskoy sfere [Experience of implementation of projects of publicprivate partnership of regions of the Russian Federation in the ecological sphere]. Regionalnaya ehkonomika. Yug Rossii, 2017, no. 3, pp. 140-150.

5. Vidyakin A.V., Latkov N.Yu. Razvitie proizvodstva moloka i molochnoy produktsii na osnove agropromyshlennoy integratsii v Kemerovskoy oblasti [Development of milk and dairy production on the basis of agro-industrial integration in the Kemerovo region]. Ekonomika i predprinimatelstvo, 2016, no. 10 (part 1), pp. 663-667.

6. Gruzdev G.V., Kirilova T.E. Predposylki importozameshcheniya molochnoy produktsii. Otsenka faktorov, okazyvayushchikh vliyanie na effektivnost proizvodstva moloka [Prerequisites of import substitution of dairy products. Assessment of the factors exerting impact on production efficiency of milk]. Vestnik NGIEHI, 2017, no. 9 (76), pp. 125-134.

7. Davydova O.A., Safronov S.L. Model otsenki konkurentosposobnosti predpriyatiya, proizvodyashchego molochnuyu produktsiyu [Model of assessment of competitiveness of the enterprise producing dairy products]. APK: problemy, sostoyanie, razvitie: $s b$. materialov I Vseros. nauch.-prakt. konf. SaintPetersburg, SPbGAU Publ., 2011, pp. 95-98.

8. Ivanov S.A. Usloviya funktsionirovaniya malykh predpriyatiy APK $\mathrm{v}$ svete poslednikh izmeneniy zakonodatelstva [Operating conditions of small enterprises agrarian and industrial complex in the light of the last changes of the legislation]. $S b$. materialov mezhdunar. nauch.-prakt. konf. FGBOU VO «Yuzhno-Uralskiy gosudarstvennyy agrarnyy universitet»: Gumanitarnyye i ekonomicheskiye nauki - agropromyshlennomu kompleksu Rossii. Troitsk, 2017, pp. 43-47.

9. Nikonorova O.S. Spetsifika funktsionirovaniya i problemy razvitiya rossiyskogo rynka moloka i molochnoy produktsii [Specifics of functioning and problem of development of the Russian market of milk and dairy products]. Ekonomicheskiye issledovaniya, 2013, no. 2. pp. 2-22.

10. Oborin M.S. Osobennosti razvitiya infrastruktury agropromyshlennogo kompleksa selskikh territoriy [Features of development of infrastructure of agro-industrial complex of rural territories]. Vestnik Volgogradskogo gosudarstvennogo universiteta. 
Е.Г. Бодрова. Некоторые проблемы развития молочного производства в России

Seriya 3, Ekonomika. Ekologiya, 2018, vol. 20, no. 2, pp. 55-64. DOI: https://doi.org/10.15688/jvolsu3.2018.2.6.
11. Pankratova
D. Yu.
Razvitie selskokhozyaystvennykh kreditnykh potrebitelskikh kooperativov na osnove primeneniya kompleksnogo podkhoda [Development of agricultural credit consumer cooperatives on the basis of application of an integrated approach]. V mire nauchnykh otkrytiy, 2015, № 11.5, pp. 1837-1846.

12. Postanovlenie Pravitelstva $R F$ ot 19 dekabrya $2014 \mathrm{~g}$. № 1421 «O vnesenii izmeneniy $v$ Gosudarstvennuyu programmu razvitiya selskogo khozyaystva $i$ regulirovaniya rynkov selskokhozyaystvennoy produktsii, syrya $i$ prodovolstviya na 2013-2020 gody». URL: http:// www.garant.ru/products/ipo/prime/doc/70727272/ (accessed 17 September 2018).

13. Prikaz Ministerstva zdravookhraneniya $R F$ ot 19 avgusta 2016 g. № 614 «Ob utverzhdenii
Rekomendatsiy po ratsionalnym normam potrebleniya pishhevykh produktov, otvechayushhikh sovremennym trebovaniyam zdorovogo pitaniya». URL: http://www.garant.ru/ products/ipo/prime/doc/71385784/ (accessed 17 September 2018).

14. Federalnaya sluzhba gosudarstvennoy statistiki [Federal State Statistics Service]. URL: http: //www.gks.ru/ (accessed 10 September 2018).

15. Shageev D.A. Povyshenie ehffektivnosti investitsionnogo proekta promyshlennogo predpriyatiya pri pomoshhi upravleniya denezhnymi potokami [Increase in efficiency of the investment project of the industrial enterprise through management of cash flows]. Vestnik Moskovskogo universiteta. Seriya 6, Ekonomika, 2017, no. 2, pp. 90-106.

16. Schwarzweller H.K., Davidson A.P. Dairy Industry Restructuring. Research in Rural Sociology and Development. N. Y., 2000, vol. 8.

\section{Information about the Author}

Ekaterina G. Bodrova, Candidate of Sciences (Economics), Associate Professor, Department of Economics and Management, International Institute of Design and Service, Voroshilova St., 12, 454014 Chelyabinsk, Russian Federation, bodrovaz@gmail.com, https://orcid.org/0000-0003-1718-8241

\section{Информация об авторе}

Екатерина Григорьевна Бодрова, кандидат экономических наук, доцент кафедры экономики и управления, Международный институт дизайна и сервиса, ул. Ворошилова, 12, 454014 г. Челябинск, Российская Федерация, bodrovaz@gmail.com, https:/orcid.org/0000-0003-1718-8241 